\section{Mood-Altering Circumstances as a Way to Encourage Creativity of University's Students}

\author{
Livia Nano, Renisa Beqiri * and Sulltana Aliaj \\ Department of Psychology and Pedagogy, University of Tirana, Albania \\ *Corresponding author
}

\begin{abstract}
.
How you feel throughout the day greatly impacts your creativity, this is confirmed by research that has explored the creative output of participants under certain mood-altering circumstances. The actual study aims to respond to the question: Is there any difference in terms of creativity expression among students' groups with different mood states in Albanian context?

From the population of students of $1^{\text {st }}$ year at Faculty of Social Sciences a random sample of 75 participants has been selected and has been randomly divided into three groups to be induced a positive, neutral or negative humor state. At first, a pre-assessment of mood state was done using PANAS questionnaire. Then, study participants were exposed to three different videos and after that, a post-assessment of mood state was conducted. In the final phase, the groups were presented with the same research task, which consisted in the appearance of an object (paper clip) and subjects were asked to list as many creative uses.

The ANOVA analysis revealed that there was a significant difference $\left(\mathrm{F}_{(2,72)}=39.688, \mathrm{p} \leq .05\right)$ among groups about their creative ideas. Participants in good mood have the highest mean score of creativity $(\mathrm{M}=6.64, \mathrm{ds}=2.361)$ compared with paticipants who self-reported a dominance of negative affect $(\mathrm{M}=4.20$, ds.=2.309) and those experiencing neutral state of affect $(\mathrm{M}=3.32 \mathrm{ds} .=1.547)$.

Giving creativity a chance to flourish by altering mood is such an important issue that may have implications not only for institutions focused on learning/education but also for business world as well.
\end{abstract}

Key words: brainstorming; emotional state; ideas; innovation, learning

\section{Introduction}

"The happiest people are those who think the most interesting thoughts"

William Lyon Phelp

When are people creative, and why? How does mood influence our thinking and behavior? These are an age-old question that philosophers, writers, and artists have struggled with since time immemorial. 


\section{4th International Conference on Future of Social Sciences 17-१९ September 2021 \\ Nice, France}

Creativity is arguably the most potent human resource both for the advancement of mankind in general and people's individual progress and success in daily life in particular. Researchers agree that at least some forms of creativity vary with mood (Akbari \& Hommel, 2012).

Many researchers have tried to answer the question of how different levels of mood influence creativity and why they impact creativity. One predominant theory is that positive mood generates a broadening of cognitive flexibility. This means that when one experiences a positive mood state, they are able to more fully experience divergent thinking, originality of thought, and the ability to elaborate on a construct (Fredrickson, 2001). Whereas, some studies show that negative, relative to neutral mood promote creative performance.

Based on the theoretical framework, the study was predicted that positive and negative moods should enhance effort on creative thinking. The goal of this paper is to determine if high creativity is dependent on elevated moods. Based on the researcher's objectives, the mood was manipulated and participants were introduced to a task that evaluated creativity after the emotional state changed.

\subsection{The concept of mood}

In the field of psychology, mood refers to a positive or negative emotional state of varying intensity that changes in response to life's circumstances. Moods are often undifferentiated, slower to change, and 'object-less' in that people may not know the cause or source of the mood (Russell, 2003). They are continually present (tonic) and shape the background of our moment-moment experience, but fluctuate over time. In contrast to moods, emotions are affective states that are directed at a specific object (e.g., being proud of something) and are phasic (i.e., have a moment of onset and then dissipate). Lane and Terry provided a definition of mood as "a set of feelings, ephemeral in nature, varying in intensity and duration, and usually involving more than one emotion" (Lane \& Terry, 2000).

When we group emotions into positive and negative categories, they become mood states because we are now looking at them more generally instead of isolating one particular emotion. So, we can think of positive affect as a mood dimension consisting of positive emotions such as excitement, self-assurance, and cheerfulness at the high end, and boredom, sluggishness, and tiredness at the low end. Negative affect is a mood dimension consisting of nervousness, stress, and anxiety at the high end, and relaxation, tranquility, and poise at the low end (Hume, 2012).

Individuals differ in their trait mood. The degree to which state mood at a given time point deviates from one's trait mood reflects effects of the situation and the interaction between person and situation (Lischetzke, 2014).

\subsection{The concept of creativity}

Human being is exceptionally blessed with the higher-level thinking abilities of creativity and problem solving. The creative process is thought to involve the capacity to shift between divergent and convergent modes of thought in response to task demands (Gabora \& Kaufman, 2010).

Defining creativity is difficult and to explain this important process the psychological schools has proposed their perspectives. The behavioral paradigm conceptualizes creativity in terms of novel associations and tries to identify the behavioral correlates of novel learning 


\section{4th International Conference on Future of Social Sciences 17-१९ September 2021 \\ Nice, France}

processes. The biological paradigm, on the other hand, looks at the physiological correlates of creative thinking and how these processes may be manifested at the level of brain structure and neural processes. The clinical paradigm looks at the extent to which creativity is associated with abnormal behavior, either as a cause or consequence of psychological disorders (Zaidel, 2014).

The cognitive paradigm emphasizes the role of cognitive processes, such as attention and memory, in regard to creativity. The developmental approach attempts to identify changes in creativity throughout the lifespan and how certain characteristics of the family (e.g., size, age, birth order) may affect levels of creativity. The educational paradigm looks at creativity in the context of formal education (e.g., primary school, secondary school, university) and attempts to assess how different teaching modalities may influence students' creativity (Forgeard \& Elstein, 2014).

Creativity is also defined as the tendency to generate or recognize ideas, alternatives, or possibilities that may be useful in solving problems, communicating with others, and entertaining ourselves and others. (Franken,1998).

\subsection{The realtionship between mood and creativity}

Human beings are a remarkably moody species. Fluctuating positive and negative affective states accompany, underlie, and color everything we think and do, and our thoughts and behaviors are often determined by spontaneous affective reactions (Adolphs \& Damasio, 2001).

Creativity is usually defined as the generation of ideas, insights, or problem solutions that are new and meant to be useful. Among the many variables that have been shown to predict creativity, mood is in the focus of the researches and practical intervention (De Dreu, Baas \& Nijstad, 2008).

How can we explain the influence of mood on information processing strategies and creativity? Early explanations emphasized the motivational consequences of good and bad moods. According to the mood maintenance/mood repair hypothesis, those in a positive mood may be motivated to maintain this rewarding state by avoiding effortful activity, such as elaborate information processing. In contrast, a negative mood should motivate people to engage in more vigilant, effortful information processing as an adaptive strategy to relieve their aversive state (Forgas,2017).

More recently, several studies also showed that the cognitive consequences of affective states may depend on whether the mood state is high or low in approach motivational intensity. For example, positive affect with low specific approach motivation toward a goal seems to broaden cognitive categorization and attention, but positive affect linked to high approach motivation towards a particular goal tends to narrow cognitive categorization (Cohn \& Fredrickson, 2009).

A lot of studies concluded that people in a positive mood are more likely to have richer associations within existing knowledge structures, and thus are likely to be more flexible and original. Positive affect impacts cognitive processing by (1) increasing the number of cognitive elements available for association; (2) defocusing attention so to increase the breadth of those elements treated as relevant to the problem; and (3) increasing cognitive flexibility (Lyubomirksy, King, \& Diener, 2005). 


\section{4th International Conference on Future of Social Sciences 17-१९ September 2021 \\ Nice, France}

Charyton et al. (2009) found that both positive and negative affect influenced the development of a creative personality in college students. Some researchers believed that the preventive-focused moods (e.g., fear, anxiety, etc.) could promote creativity. Meanwhile, this kind of negative mood in uncertain situations is likely to be a source of creativity. Similarly, many studies have shown that negative mood experiences could promote creative performance during the idea generation. Other researchers believed that the negative mood would improve the originality and flexibility of creative ideation. It is possible that mild negative mood can enhance creativity by generating powerful thinking and strengthening perseverance (Drapeau, 2010).

\section{Methods}

\subsection{Research design}

The main object of this research is the analysis of how the state of humor affects the giving of creative ideas for solving a problem, as well as the implementation of an intervention to verify that the state of humor can change through grounded interventions. in the presentation of video clips with different emotional tonalities.

To fulfill the research object of the study, the selected methodology is the mixed methodology, which includes the combination of quantitative and qualitative methodology for data collection. The integration of data in two forms, enables researchers to enrich the findings of their study, as well as to gain a level of a deeper understanding of the study phenomenon. This combination of data integrates the strengths of qualitative and quantitative research, as well as compensates for their weaknesses, providing a comprehensive understanding of the study topic (Halcomb \& Hickman, 2015), as well as expanding the research space for a certain issue, as they provide specific recommendations for further research. The research design of this study is a quasi-experimental Pre-Post Test, without a control group. A quasi-experimental design aims to establish a cause-and-effect relationship between two variables.

Thus, in this research qualitative analysis refers to the use of The Alternative Uses Test to measure new creative ideas, while quantitative analysis refers to the use of the PANAS selfreport questionnaire, to measure mood before and after the intervention.

\section{Sampling Procedures and Sample}

The participants in this study are students from the Faculty of Social Sciences of the University of Tirana. The sample consists of 75 subjects aged 18-22 years. Two criteria were set to select this sample:

Subjects should not be students of Psychology

Subjects should have the same age

Convenience sampling was used for the selection of subjects and then they were randomly divided into three experimental groups, with 25 subjects for each group. 


\section{4th International Conference on Future of Social Sciences 17-१९ September 2021 \\ Nice, France}

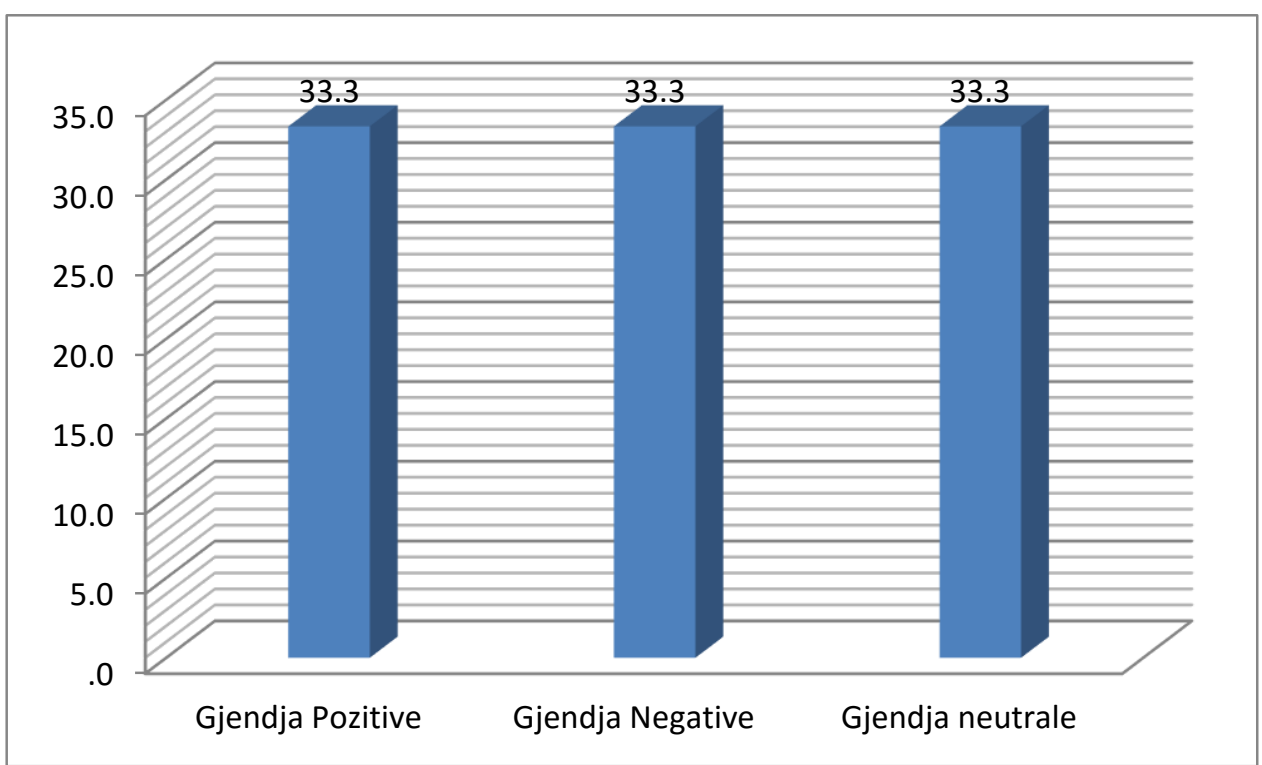

Subjects were informed about all ethical issues and this study was preceded by a pilot phase.

\subsection{Instruments and Materials}

Positive and Negative Affect Scales (PANAS)

Positive and Negative Affect Schedule (PANAS). The PANAS (Watson \& Clark, 1988) is a 20-item list of positive and negative adjectives scored on a 5-point scale that asks the participant to respond to given words describing emotions and feelings and indicate to what degree the participant feels this way $(1=$ very slightly, not at all; $2=$ a little; $3=$ moderately; 4 = quite a bit; $5=$ extremely) for a given time period (at the moment) (Harmon-Jones \& Harmon-Jones, 2010). The positive affect items, which are interspersed with the negative affect items, include interested, excited, strong, enthusiastic, proud, alert, inspired, determined, attentive, and active. The negative affect items are distressed, upset, guilty, scared, hostile, irritable, ashamed, nervous, jittery, and afraid. It comprises of 10 positive and 10 negative adjectives rated on a Likert scale from 1 (very little or not at all) to 5 (very or extremely) (Osin, 2021).

\section{The Alternative Uses Test}

The Alternative Uses Test designed by J.P. Guilford in 1967, the Alternative Uses Test asks you to think of as many uses as possible for a simple object. The test measures divergent thinking, as it is looking for the participant to generate lots of ideas. The Alternative Uses test is used frequently in creativity researches.

Results of the test are measured across four sub-categories:

- Fluency - the number of alternative uses you can think of;

- Originality - how unusual those uses are - evidence of 'thinking different';

- Flexibility - the range of ideas, in different domains and categories;

- Elaboration - level of detail and development of the idea (Madore, Jing \& Schacter, D. 2016). 


\section{4th International Conference on Future of Social Sciences 17-१९ September 2021 \\ Nice, France}

Mood induction videos.

Studies have used several means to induce affect. According to Lazar et al. (2012) Positive Affect (PA) scores were higher following a positive affect film clip and lowest following a negative affect film clip. Similarly, Negative Affect (NA) scores were highest following a negative affect film clip and lowest following a positive affect clip. The positive video clip induced a stronger positive affect and the negative video clip induced a stronger negative affect in comparison with other methods uses to manipulate the mood. Video clip information is perceived by two information roots, the auditory root as well as the visual root (Kandel et al., 2013).

Based on this findings, in our study was decide to use exactly 3 video clips, as a primary methods of mood changes at participants.

\subsection{Procedures}

The study was conducted in students of Social Science Faculty at University of Tirana, Albania. The subjects were separated randomly into three groups, with 25 subjects in each experimental group. The following tables provide information on the demographic data of the subjects in each experiment group.

Table 1.

Demographic data for the experimental group 1. Positive condition

\begin{tabular}{llll}
\hline & & N(sample) & $(\mathbf{\% )}$ \\
\hline Gender & Female & 18 & 72 \\
Age & Male & 7 & 28 \\
\hline
\end{tabular}

Table 2.

Demographic data for the experimental group 2. Negative condition

\begin{tabular}{llll}
\hline & & N(sample) & $\mathbf{( \% )}$ \\
\hline Gender & Female & 17 & 68 \\
Age & Male & 8 & 32 \\
\hline
\end{tabular}

Table 3.

Demographic data for the experimental group 3. Neutral state

\begin{tabular}{llll} 
& & N(sample) & $(\mathbf{0 )}$ \\
\hline Gender & Female & 25 & 100 \\
& Male & 0 & 0 \\
\hline Age & $18-22$ years & 25 & 100 \\
\hline
\end{tabular}

The subjects were informed about the research and given their consent to be part of the study. 


\section{4th International Conference on Future of Social Sciences 17-19 September 2021 \\ Nice, France}

To conduct this study, the subjects underwent 4 stages of application:

First, a pre-assessment of mood state was done using the PANAS questionnaire. The instrument was administered individually, by used code numbers for each participant.

Second, the subjects are presented with the relevant videos for each group of the experiment. The participants part of the positive group were exposed to a comedian part by Mr. Bean; the participants of the neutral group watched an informative video about The Louvre Museum and a video from The War of Kosovo was presented to participants of the negative humor manipulation group. The videos had the same duration (7 minutes).

Third, to evaluate the impact of videos on the mood of participants, the administration of PANAS was repeated.

In the end, the students were introduced to the paper clip object and asked to list as many creative ways as possible to use this object. This request was part of Guilford's Alternative Uses Test administration.

\section{Results}

The following results show the main findings of the study regarding the change of mood before and after the implementation of the intervention respectively in the three experimental groups. They also show the impact of intervention in giving creative ideas. Quantitative results from the data collection of PANAS (Positive and Negative Affect Scales) in Pre - Post Test Paired Samples Test was used to measure the differences in the mean change of the initial mood state at time $\mathrm{T} 1$ and that after the intervention, at time T2, within the groups of induced mood states, for each group separately (positive, negative, and neutral), both in experiencing negative and positive emotions. More specifically, in terms of differences in time $\mathrm{t} 1$ and $\mathrm{t} 2$ of experiencing positive emotions, in the group with a positive mood, higher levels of positive emotions were experienced in time $\mathrm{t} 2(\mathrm{M}=-2.680, \mathrm{ds}=5.146)$ and with confidence interval CI $[-4.804 ;-.556]$ to positive state, compared to time $\mathrm{t} 1 \mathrm{t}(\mathrm{df}=24)=-$ $2.604, \mathrm{p} \leq .05$ ). While experiencing negative emotions in this group, from time $\mathrm{t} 1$ to time $\mathrm{t} 2$, based on the significance $\mathrm{p}$, we see that there are significant differences $(\mathrm{t}(\mathrm{df}=24)=4.367$, $\mathrm{p} \leq .05)$ between the result of negative emotions at time t1 and time $\mathrm{t} 2(\mathrm{M}=2.04, \mathrm{ds}=2.336)$ and with CI confidence interval $[1.076 ; 3.004]$ to the positive state. So, the experience of negative emotions is lower in time $\mathrm{t} 2$ compared to time $\mathrm{t} 1$.

Differences in the time $t 1$ and $t 2$ of experiencing positive emotions, in the group with negative mood, show that there are significant differences $(\mathrm{t}(\mathrm{df}=24)=5.550, \mathrm{p} \leq .05)$ between the result of positive experiences in time $\mathrm{t} 1$ and positive experiences at time $\mathrm{t} 2(\mathrm{M}=6.4, \mathrm{ds}=$ 5.766) and with CI confidence interval $[4.02 ; 8.78]$ to the negative state. These data show that the experience of positive emotions is lower at times $t 2$ than at times $t 1$. As for negative emotions, based on the significance $\mathrm{p}$ we see that there are statistically significant differences $(\mathrm{t}(\mathrm{df}=24)=-9.743, \mathrm{p} \leq .05)$ between the result of experiencing negative emotions at time $\mathrm{t} 1$ and time $\mathrm{t} 2(\mathrm{M}=-13.560, \mathrm{ds}=6.959)$, with $\mathrm{CI}$ confidence interval $[-16.432 ;-10.688]$ to the negative state. These data show that negative emotions are experienced more successfully at time $\mathrm{t} 2$ than at time $\mathrm{t} 1$. 


\section{4th International Conference on Future of Social Sciences 17-१९ September 2021 \\ Nice, France}

Regarding the group with neutral mood, the results show that there is no statistically significant difference between experiencing positive emotions at time $\mathrm{t} 1 \mathrm{M}=31.32$, $\mathrm{ds}=$ 6.866) and at time $\mathrm{t} 2$ with $\operatorname{Min}=16, \operatorname{Max}=48$ with a average $(\mathrm{M}=30.16$, ds $=7.941)$, also there are no statistically significant differences in the levels of experiencing negative emotions at time $\mathrm{t} 1$ is $\mathrm{Min}=10$, $\mathrm{Max}=34$ with an average $(\mathrm{M}=14.76, \mathrm{ds}=5.747)$ and in time $\mathrm{t} 2(\mathrm{M}=14.52, \mathrm{ds}=5.832)$.

To identify if there are significant differences between the subjects of the three experimental groups in terms of the level of experiencing positive emotions at time t2, ANOVA was used. The results show statistically significant differences between the subjects $(\mathrm{F}(2,72)=12,835$ $\mathrm{p} \leq .05)$ since the value of $\mathrm{p}$ is less than .05 . Thus, the positive emotions experienced at time $t 2$ appear higher in the group with a positive state with an average $(\mathrm{M}=33.52$, ds $=5.945)$ compared to the group with a negative and neutral state, as shown in Table 4.

Table 4: ANOVA test and Magnitude of the Effect on the positive emotions at time $\mathbf{t} 2$ according to the mood state (positive / negative / neutral)

\begin{tabular}{cccccc}
\hline & $\begin{array}{c}\text { Sum of } \\
\text { Squares }\end{array}$ & df & $\begin{array}{c}\text { Mean } \\
\text { Square }\end{array}$ & F & p \\
\hline $\begin{array}{c}\text { Between } \\
\text { Groups } \\
\text { Within }\end{array}$ & 1218.480 & 2 & 609.240 & 12.8 & .000 \\
$\begin{array}{c}\text { Groups } \\
\text { Total }\end{array}$ & 3417.600 & 72 & 47.467 & & \\
\hline
\end{tabular}

Whereas, to see the differences in the experience of negative emotions in the three groups at time $\mathrm{t} 2$, the results of the ANOVA test show statistically significant differences between the subjects $(F(2.72)=39.688$, p.05) in terms of level of negative aspects as the value of $p$ is less than .05. Thus, negative emotions at time $\mathrm{t} 2$ appear higher in the negative state with an average $(\mathrm{M}=27.24, \mathrm{ds}=9.203)$ compared to the positive and neutral state, as shown in Table 5.

Table 5: ANOVA test and the magnitude of the effect on positive emotions at time t2 by state (positive / negative / neutral)

\begin{tabular}{lccccc}
\hline & Sum of Squares & df & $\begin{array}{c}\text { Mean } \\
\text { Square }\end{array}$ & F & P \\
\hline Between Groups & 3482.640 & 2 & 1741.320 & 39.688 & .00 \\
Within Groups & 3159.040 & 72 & 43.876 & & \\
Total & 6641.680 & 74 & & & \\
\hline
\end{tabular}

The data collected from the subjects participating in this study, were analyzed through the ANOVA test to see if there are significant differences between the subjects in terms of levels of creativity. From the table below we see that statistically significant differences appear between the subjects $(\mathrm{F}(2,72)=39,688, \mathrm{p} \leq .05)$ in terms of the level of creativity as the value 


\section{4th International Conference on Future of Social Sciences 17-19 September 2021 \\ Nice, France}

of $\mathrm{p}$ is less than .05 . The result shows that creativity is higher in the positive state with an average $(\mathrm{M}=6.64, \mathrm{ds}=2.361)$ compared to the negative and neutral state, as shown in Table 6.

Table 6: ANOVA test of differences in mean creativity by mood state (positive / negative / neutral)

\begin{tabular}{lccccc}
\hline & N & Mean & $\begin{array}{c}\text { Standard } \\
\text { Deviation }\end{array}$ & F & P \\
\hline Possitive Mood & 25 & 6.64 & 2.361 & 16.683 & .000 \\
Negativ Mood & 25 & 4.20 & 2.309 & & \\
Neutral Mood & 25 & 3.32 & 1.547 & & \\
Total & 75 & 4.72 & 2.512 & & \\
\hline
\end{tabular}

At last, the Pearson correlation was used to explore the relationship between creativity and positive emotions experienced in all three experimental groups. From the table below we see that there is an important positive relationship of positive emotions with creativity $(\mathrm{r}(\mathrm{n}=75)$ $=.229, \mathrm{p} \leq .05)$. The result shows that with the increase of experiencing positive emotions, the levels of creativity also increase, as shown in Table 7.

Table 7: Pearson correlation between creativity and positive / negative aspects

Creativity

\begin{tabular}{llc}
\hline Possitive emotions - Time 2 & Pearson Correlation & $.229^{*}$ \\
& Sig. (2-tailed) & .049 \\
Negative emotions - Time 2 & $\mathrm{N}$ & 75 \\
& Pearson Correlation & -.043 \\
& Sig. (2-tailed) & .717 \\
& $\mathrm{~N}$ & 75 \\
\hline
\end{tabular}

*. Correlation is significant at the 0.05 level (2-tailed).

Qualitative results from The Alternative Uses Test

The data collected by the Alternative Uses Test, were analyzed based on the categories defined by the user manual of this questionnaire.

According to the analysis of the data in the first group of the experiment (positive mood), the number of creative ideas given on the ways of using the paper clip was the highest in number, respectively there are 166 ideas in total, with an average of 6.6 ideas. The ideas were very original, practical, and explained in detail. A very small number of general ideas were observed (only 3 of them), and a high predisposition to report usage modes with different words and complete sentences. More specifically, the examples are presented in Table 8. 


\section{4th International Conference on Future of Social Sciences \\ 17-19 September 2021 \\ Nice, France}

Table 8: Concrete examples of reports in the positive experimental group

\begin{tabular}{|c|c|}
\hline Categories & Examples \\
\hline - Fluency & $\begin{aligned} 166 \text { ideas } & \\
& >\text { Paper clips (25 subjects) } \\
& >\text { To make different accessory like pendant or bracelet (10 } \\
& \text { subjects) } \\
> & \text { Used as a hair clip (12 subjects) }\end{aligned}$ \\
\hline - Originality & 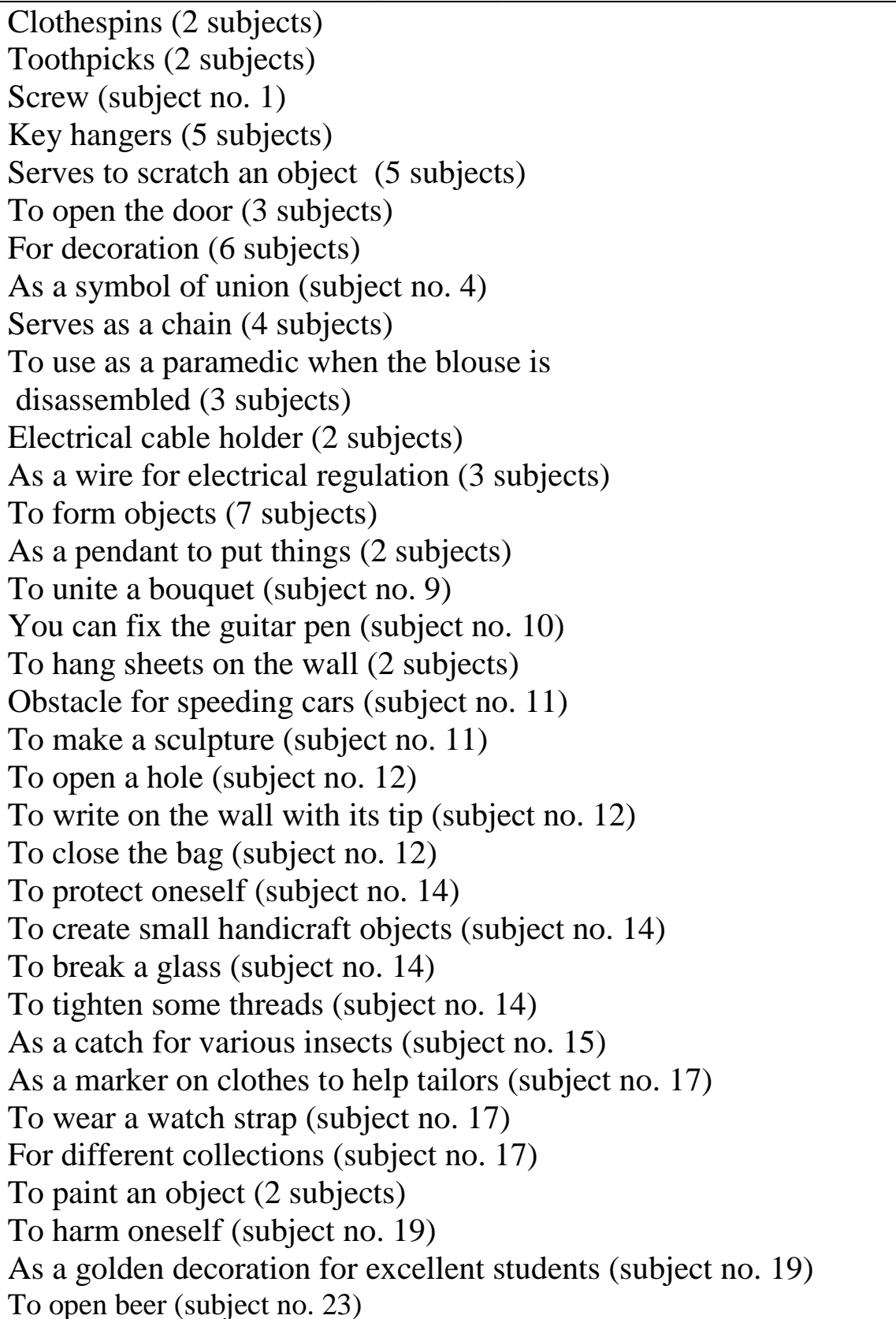 \\
\hline - Flexibility & $\begin{array}{l}\text { 1. To catch letters } \\
\text { 2. To make different accessories } \\
\text { 3. To catch different objects } \\
\text { 4. Serves to scratch } \\
\text { 5. To hang different objects } \\
\text { 6. Unique ideas }\end{array}$ \\
\hline
\end{tabular}




\section{4th International Conference on Future of Social Sciences 17-१९ September 2021

\begin{tabular}{|l|l|}
\hline Elaboration & $\begin{array}{l}\text { Sometimes when the body itches it uses it as an object to itch the } \\
\text { body (subject no. 2) } \\
\text { You can make long threads and use it as a ruler (subject no. 5) } \\
\text { You can use it when painting nails (especially for French nails) to } \\
\text { protect the nail part (subject no. 5) } \\
\text { To divide the pages of a book so that it is easier to learn (4 subjects) } \\
\text { To open the place where the phone card is inserted, for example } \\
\text { iphone (2 subjects) } \\
\text { To clean tight spaces where no cloth or broom is inserted (3 } \\
\text { subjects) } \\
\text { To fasten a blouse appropriately (3 subjects) } \\
\text { To catch a handkerchief held on the head (subject no. 8) } \\
\text { Obstacle for speeding cars (subject no. 32) } \\
\text { To catch sheets that are important on the wall (subject no. 13) } \\
\text { To catch the leaves of trees and to select them (subject no. 15) } \\
\text { To give excellent students as a gold decoration (subject no. 19) } \\
\text { To mark clothes, mainly used by tailors (subject no. 17) }\end{array}$ \\
\hline
\end{tabular}

Relating to experimental group 2 (negative mood), a total of 101 ideas were collected, with an average of 4.04 ideas. Compared to the positive experimental group, there is a reduced number of ideas listed and an increase in the number of general ideas, respectively 13 general ideas and only 26 specific ideas. Of these, very few of the ideas have been explained in detail. The following table presents some concrete examples:

Table 9: Concrete examples of reports in the negative experimental group

\begin{tabular}{|c|c|}
\hline Categories & Examples \\
\hline - Fluency & 101 ideas \\
\hline - Originality & $\begin{array}{l}\text { Toothpicks (subject } 1 \text { ) } \\
\text { To harass friends (subject } 1 \text { ) } \\
\text { To connect two objects to each other (2 subjects) } \\
\text { To drill various objects (subject 2) } \\
\text { To catch clothes (subject 2) } \\
\text { As a bottle opener (subject } 2 \text { ) } \\
\text { To engrave (subject } 2 \text { ) } \\
\text { To catch girls hair (subject } 6 \text { ) } \\
\text { To keep the tie behind the shirt (subject } 6 \text { ) } \\
\text { To use as a hook (subject 9) } \\
\text { To clean nails ( } 3 \text { subjects) } \\
\text { To write on the walls (subject } 14 \text { ) } \\
\text { To form geometric bodies (subject } 14 \text { ) } \\
\text { To build a mosaic (subject } 14 \text { ) } \\
\text { To replace the shirt button (subject } 16 \text { ) } \\
\text { To tear up letters (subject } 17 \text { ) } \\
\text { To exercise power over another object (4 subjects) } \\
\text { To scratch the bank (subject } 17 \text { ) }\end{array}$ \\
\hline
\end{tabular}




\section{4th International Conference on Future of Social Sciences 17-19 September 2021

\begin{tabular}{|l|l|}
\hline \multirow{1}{*}{ Flexibility } & $\begin{array}{c}\text { To hold the broken pocket of the bag (subject 18) } \\
\text { To join two corners of torn clothes (subject 20) } \\
\text { To glue it somewhere as a holder (subject 20) } \\
\text { To paint (3 subjects) } \\
\text { To use for combination in clothing (subject 23) } \\
\text { To entertain children by creating toys (subject 23) } \\
\text { To create sounds from their collision (subject 23) }\end{array}$ \\
\hline Elaboration & $\begin{array}{l}\text { 1 To catch cards, various documents } \\
\text { 2. To hold the keys } \\
\text { 3. To play } \\
\text { 4. For different decorations } \\
\text { 5. To use it as anti-stress or various games } \\
\text { 6. For creating different objects } \\
\text { 7.Unique ideas }\end{array}$ \\
\hline $\begin{array}{l}\text { You can run it on both sides to clean your teeth or to scratch them } \\
\text { better (Subject No. 1) } \\
\text { Fold it and use it as a hook explaining it with figures (Subject no. 9) } \\
\text { It can also be used to create if we can say different objects or items, } \\
\text { always at home (Subject No. 16) } \\
\text { It can be used when giving a speech in front of many people if we } \\
\text { have emotion / anxiety. Dealing with opening or closing it while } \\
\text { talking helps you (Subject No. 23) } \\
\text { Accessory for clothes, if it is colored but also to give it a personal } \\
\text { touch (Subject No. 23) }\end{array}$ \\
\hline
\end{tabular}

In experimental group 3 (neutral mood), the total number of ideas for how to use the paper clip is 83 , with an average of 3.3 ideas. Of these, 9 general ideas and 18 specific ideas were reported. Only 3 of them are explained in detail. The following table presents some concrete examples:

Table 10: Concrete examples of reports in the neutral experimental group

\begin{tabular}{|c|l|}
\hline Categories & Examples \\
\hline$\bullet \quad$ Fluency & 91 ideas \\
\hline Originality & $\begin{array}{l}\text { To tighten the glasses with its tip (subject 16) } \\
\text { To play the guitar (subject 16) } \\
\text { To catch clothes (2 subjects) } \\
\text { To fasten the clock (subject 20) } \\
\text { To erode (subject 23) } \\
\text { To itch the ears (subject 26) } \\
\text { To fix the sheet to the wall (subject 2) } \\
\text { To create different shapes with it (subject 7) } \\
\text { To put as a weight on a light object not to be picked up by } \\
\text { the wind (subject } 8 \text { ) } \\
\text { To catch something that is difficult to catch by hand } \\
\text { (subject 8) }\end{array}$ \\
\hline
\end{tabular}




\section{4th International Conference on Future of Social Sciences 17-१९ September 2021

\begin{tabular}{|c|l|}
\hline & \multicolumn{1}{|c|}{$\begin{array}{c}\text { To put two hangers together (subject 9) } \\
\text { To remove nail polish from the nails (subject 11) } \\
\text { In cases of physical experiments it is used as a conductor } \\
\text { of electricity (subject 12) } \\
\text { You can make photo frames (subject 13) } \\
\text { To make different shapes with plasticine (3 subjects) }\end{array}$} \\
\hline - Flexibility & $\begin{array}{l}\text { 1. To capture letters, documents, etc. } \\
\text { 2. To catch clothes, hair } \\
\text { 3. To make jewelry } \\
\text { 4. To use as a decorator } \\
\text { 5. To replace various objects } \\
\text { 6. To form different objects } \\
\text { 7.Unique ideas }\end{array}$ \\
\hline Elaboration & $\begin{array}{l}\text { We can use it on the Christmas tree as an additional and special } \\
\text { accessory (Subject 7) } \\
\text { In the case of physical experiments, we use it as a conductor of } \\
\text { electricity since it is composed of metal (Subject 12) } \\
\text { To put it as a weight on something that the wind does not take } \\
\text { (Subject 8) }\end{array}$ \\
\hline
\end{tabular}

\section{Discussion}

This study explored the impact that an intervention has on changing mood in subjects at a young age. From the results of this study, it was noticed that the induction of a positive mood in the subjects would increase the levels of creative thinking and unique alternatives of problem-solving. According to studies, positive mood indicates that the situation is safe and may encourage a relaxed and playful approach to situations, using simplifying heuristics, exploring novel possibilities, and elaborating on unusual, creative associations.

On the other hand, the induction of negative humor in the subjects would affect the number of general creative ideas, but also the unique ones for solving a problem. This finding is supported by other studies, which report that a negative mood informs the individual that the current situation is problematic and that negative outcomes are possible, which may encourage them to avoid such risky approaches, favouring instead a more exacting, detail oriented, processing style.

\section{Conclusions}

The study analyzed how mood affects the creativity at a sample of students from the Faculty of Social Sciences, University of Tirana. The design of the research was quasi experiment, pre-post test design.

To indicate a specific emotional state at students was chosen short video, that have resulted effective to change the mood of participants. Divided into three groups, the participants have showed Mr. Bean comedy (positive mood); an informative sequence about the Museum of Louvre (neutral mood) and with the War at Kosovo video. The findings provided from pre and post assessment with PANAS questionnaire have evidenced the difference in the mood of the students according to their group. After the intervention, the participants at positive mood 


\section{4th International Conference on Future of Social Sciences 17-१९ September 2021 \\ Nice, France}

group, reported for increase of positive emotions and decrease of negative emotions; the participants at negative mood group have showed increase of negative emotions and decrease of positive emotions and the participants at neutral group didn't have significant differences.

To explore the impact of mood at creativity The Alternative Uses Test was applied. The participants, for a period time of five minutes should listed as much as possible creative uses of paper clip. Based on data analyzed, the subject part of positive mood group has shared more creative ideas. Also, in terms of originality, fluency, elaboration and flexibility there is higher number of ideas compared to the other two groups. It is important to empathies that the subject at negative mood group was more creative compared with subject at neutral group. This conclusion underlines the importance of emotion at the human motivation to solve problems in creative manners.

The role of emotion on creative cognition is critical and emerging as topic in the research on creativity, as everyday emotional states can influence ideas that come to mind, and thereby influence the decision that rely on those ideas. The findings of the study appear to be consistent with certain past findings on the relationship between moods and creativity, were people that experience emotion tend to be more creative. From a practical viewpoint, these data have implications for settings in which creativity and innovation are important, such as school or organizations, Understanding and creating strategies that improve emotional state to increase creativity should have a huge focus at other implementations in a large number of populations.

\section{References}

Adolphs, R., Damasio, A.R., 2001. The interaction of affect and cognition: a neurobiological perspective. In: Forgas, J.P. (Ed.), Handbook of Affect and Social Cognition. Erlbaum, Mahwah, NJ, pp. 27-49

De Dreu, C. K., Baas, M., \& Nijstad, B. A. (2008). Hedonic tone and activation level in the mood-creativity link: toward a dual pathway to creativity model. Journal of personality and social psychology, 94(5), 739.

Drapeau, C. W. (2010). Creativity and Positive Affect: Is High Creativity Dependent on an Elevated Mood?. IU South Bend Undergraduate Research Journal, 10, 83-90.

Cohn, M. A., \& Fredrickson, B. L. (2009). Positive emotions. Oxford handbook of positive psychology, 2, 13-24.

Franken, R. E. (1998). Human motivation. Pacific Grove, California: Brooks/Cole Publishing Company

Forgas, J. P. (2017). Mood effects on cognition: Affective influences on the content and process of information processing and behavior. Emotions and affect in human factors and human-computer interaction, 89-122.

Forgeard, M. J., \& Elstein, J. G. (2014). Advancing the clinical science of creativity. Frontiers in psychology, 5, 613.

Fredrickson, B. L. (2001). The role of positive emotions in positive psychology: the broadenand-build theory of positive emotions. American psychologist, 56(3), 218. 


\section{4th International Conference on Future of Social Sciences 17-१९ September 2021 \\ Nice, France}

Gabora, L., \& Kaufman, S. B. (2010). Evolutionary approaches to creativity.

Halcomb, E. J., \& Hickman, L. (2015). Mixed methods research.

Harmon-Jones, E., \& Harmon-Jones, C. (2010). On the relationship of trait PANAS positive activation and trait anger: Evidence of a suppressor relationship. Journal of Research in Personality, 44(1), 120-123.

Hume, D. (2012). Emotions and moods. Organizational behavior, 258-297.

Kandel, E. R., Markram, H., Matthews, P. M., Yuste, R., \& Koch, C. (2013). Neuroscience thinks big (and collaboratively). Nature Reviews Neuroscience, 14(9), 659-664.

Lane, A. M., \& Terry, P. C. (2000). The nature of mood: Development of a conceptual model with a focus on depression. Journal of applied sport psychology, 12(1), 16-33.

Lischetzke, T. (2014). Mood. In A. C. Michalos (Ed.), Encyclopedia of quality of life and well-being research (pp. 4115-4120). Dordrecht, Netherlands: Springer

Lyubomirsky, S., King, L., \& Diener, E. (2005). The benefits of frequent positive affect: Does happiness lead to success?. Psychological bulletin, 131(6), 803.

Madore, K. P., Jing, H. G., \& Schacter, D. L. (2016). Divergent creative thinking in young and older adults: Extending the effects of an episodic specificity induction. Memory \& cognition, 44(6), 974-988.

Osin, E. (2012). Measuring positive and negative affect: Development of a Russian-language analogue of PANAS. Psychology. Journal of Higher School of Economics, 9(4), 91-110.

Russell, J. A. (2003). Core affect and the psychological construction of emotion. Psychological review, 110(1), 145.

Zaidel, D. W. (2014). Creativity, brain, and art: biological and neurological considerations. Frontiers in human neuroscience, 8, 389. 